FACTA UNIVERSITATIS

Series: Mechanical Engineering Vol. 16, Nº 2, 2018, pp. 193 - 201

https://doi.org/10.22190/FUME180526025N

Original scientific paper

\title{
PARAMETERS FORECASTING OF LASER WELDING BY THE ARTIFICIAL INTELLIGENCE TECHNIQUES
}

\author{
911.2:556
}

\author{
Vlastimir Nikolić ${ }^{1}$, Miloš Milovančević ${ }^{1}$, Dalibor Petković ${ }^{2}$, \\ Dejan Jocić ${ }^{1}$, Milan Savić ${ }^{1}$ \\ ${ }^{1}$ University of Niš, Faculty of Mechanical Engineering, Serbia \\ ${ }^{2}$ University of Niš, Faculty of Pedagogical Sciences, Serbia
}

\begin{abstract}
Laser welding process is used in many industrial sectors. One of the most important aspects of the laser welding quality refers to the geometrical and mechanical properties of welding joints. In order to develop optimal conditions for the laser welding process it is desirable to know in advance which machining parameters to select. Though there are manuals which recommend specific parameters combinations for the desired laser welding quality it is difficult to cover all possible combinations because of the process nonlinearity. Therefore, in this study the main aim is to establish an algorithm for optimal parameters forecasting of the laser welding process. The algorithm is based on an artificial intelligence approach. The main goal is to forecast the geometrical parameters of the welding joints like front width, front heights, back width and back heights of the welding joints. Experimental process was performed in order to acquire training and testing data of the laser welding process. The obtained results could be of practical importance for engineers in industry.
\end{abstract}

Key Words: Laser Welding, Forecasting, Artificial Intelligence, Welding Joint

\section{INTRODUCTION}

The laser welding process is used in manufacturing engineering as an advanced process. One of its main merits is a high density of power, high productivity and high penetration. There is also a narrow heath-affected zone which is also a very important factor. However, before proceeding to the process itself, one needs to select optimal machining parameters in order to get the best performances of the welding joints. There are number of parameters which could have high influence on the laser welding quality.

Received May 26, 2018 / Accepted July 15, 2018

Corresponding author: Vlastimir Nikolić

University of Niš, Faculty of Mechanical Engineering, A. Medvedeva 14, 18000 Niš, Serbia

E-mail: vnikolic@masfak.ni.ac.rs 
The quality of the welding joints could be determined based on mechanical and geometrical parameters of the weld. Laser power, welding speed, focal position and gap have high relevance for the mechanical and geometrical parameters of the weld. It is a difficult test to select optimal machining parameters in order to get the best weld quality. For such a purpose many engineers empirically select machining parameters. However, the empiric selection is prone to errors since it is affected by engineers' knowledge of the process.

There are different mechanical and geometrical parameters which are investigated by researchers. According to the results reported by Schweier et al. [1] there are three mechanisms of spatter formation in the laser welding process. These spatter formations are caused by material ablation, by laser spot entry into the melting spot and by dynamics of melt spot. One of the important factors during the laser welding process with high power CO2 laser is laser-induced plasma [2]. Mi et al. [3] used a finite element code to predict temperature, phase fraction and stress fields during the laser welding process. Taguchi based grey relational analysis was used by Shanmugarajan et al. [4] for optimization of the laser welding process; it showed that the obtained results were closely correlated to the predicted values. Differences in interactions between the laser and the plasma arc were investigated by Chen et al. [5]. Cai et al. [6] investigated the laser effect on the welding process. Chen et al. [7] studied gap tolerance of the butt laser joint. Using a high speed video during CO2 laser-MAG hybrid welding of E36 steel, Huang et al. [8] studied droplet transfers at different positions.

In spite of different approaches for selection of the optimal laser welding parameters there are no investigations yet which can be used universally for all different materials and process. Hence in this study the main aim is to forecast optimal laser welding parameters by the algorithms which are based on the artificial intelligence (AI) approach. The AI approaches are useful since they require no internal physical knowledge of the process. There is only the need to acquire input-output data pairs for training and testing process of the algorithms. The algorithms are used for forecasting of laser welding geometrical parameters. Three AI approaches are used in this study:

- Extreme learning Machine (ELM) [9, 10],

- Artificial neural network (ANN) [11], and,

- Genetic programming (GP) [12].

As input parameters, laser power, welding speed, focal position and gap are used. Front width, front height, back width and back height are used as output parameters. The parameters present geometrical parameters of the welding joints and represent important quality indicators of the laser welding process.

\section{EXPERIMENTAL MEASUREMENT}

For an experimental measurement procedure low carbon steel Q235 and stainless steel SUS301L-HT are used. Fig. 1 gives a schematic view of the laser welding process.

Fiber laser IPG YLR-4000 is used during the laser welding process. The laser has wavelength of $1.1 \mu \mathrm{m}$. Lens focal length is $220 \mathrm{~mm}$ and diameter spot is focused to 0.2 $\mathrm{mm}$. A set of input machining parameters are determined based on the previous studies in literature. Table 1 shows a set of input and output parameters used in this study. 


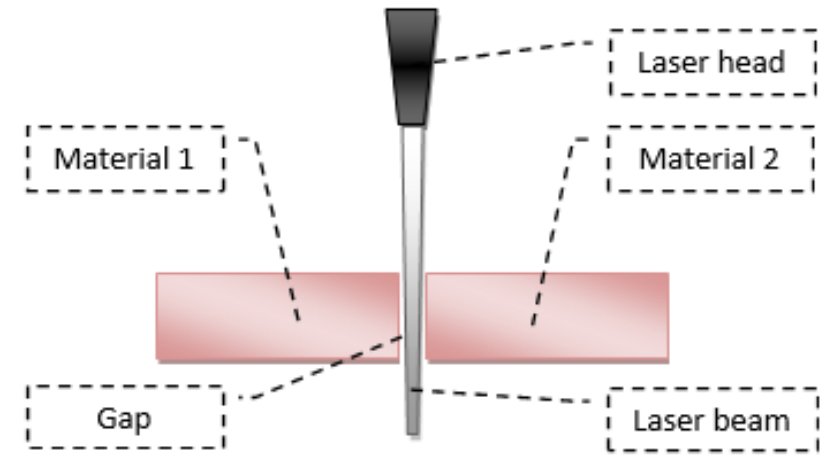

Fig. 1 Schematic view of the laser welding process

Table 1 Main parameters used in this study

\begin{tabular}{llcc}
\hline Inputs and outputs & Parameters description & Min & Max \\
\hline Input parameter 1 & Laser power $(\mathrm{W})$ & 1500 & 3500 \\
Input parameter 2 & Welding speed $(\mathrm{m} / \mathrm{min})$ & 2.5 & 3.5 \\
Input parameter 3 & Focal position $(\mathrm{mm})$ & -3 & 1 \\
Input parameter 4 & Gap $(\mathrm{mm})$ & 0 & 0.1 \\
Output parameter 1 & Weld front width $(\mu \mathrm{m})$ & 800 & 1600 \\
Output parameter 2 & Weld back width $(\mathrm{mm})$ & 0 & 1400 \\
Output parameter 3 & Weld front height $(\mathrm{mm})$ & -200 & 50 \\
Output parameter 4 & Weld back height $(\mathrm{mm})$ & -400 & 300 \\
\hline
\end{tabular}

Geometrical parameters are used as output indicators for the laser welding quality estimation and forecasting. Fig. 2 shows the positions of the geometrical parameters.

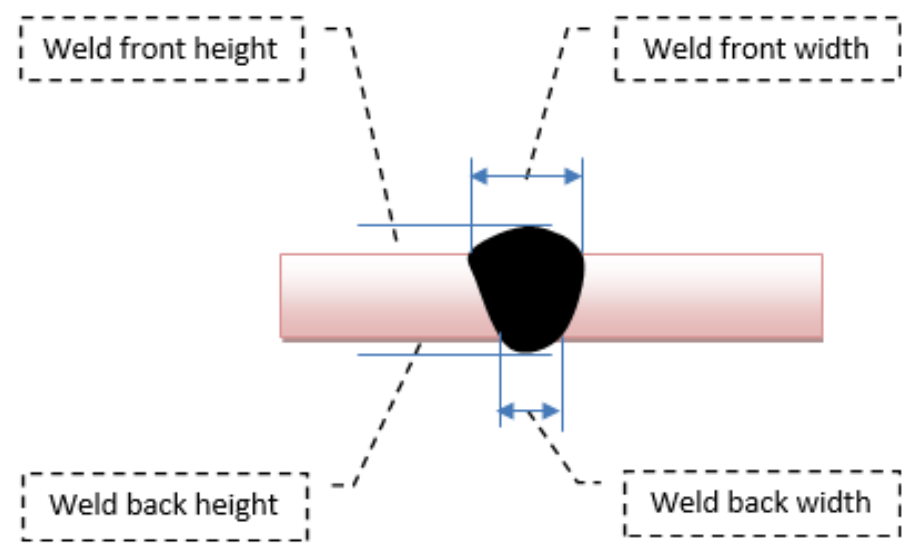

Fig. 2 Geometrical parameters of weld 


\section{EXTREME LEARNING MACHINE}

A fuzzy inference system in MATLAB software is employed in the whole process of the ANFIS training and evaluation. An ANFIS network for 2 input variables is depicted in Fig. 3.

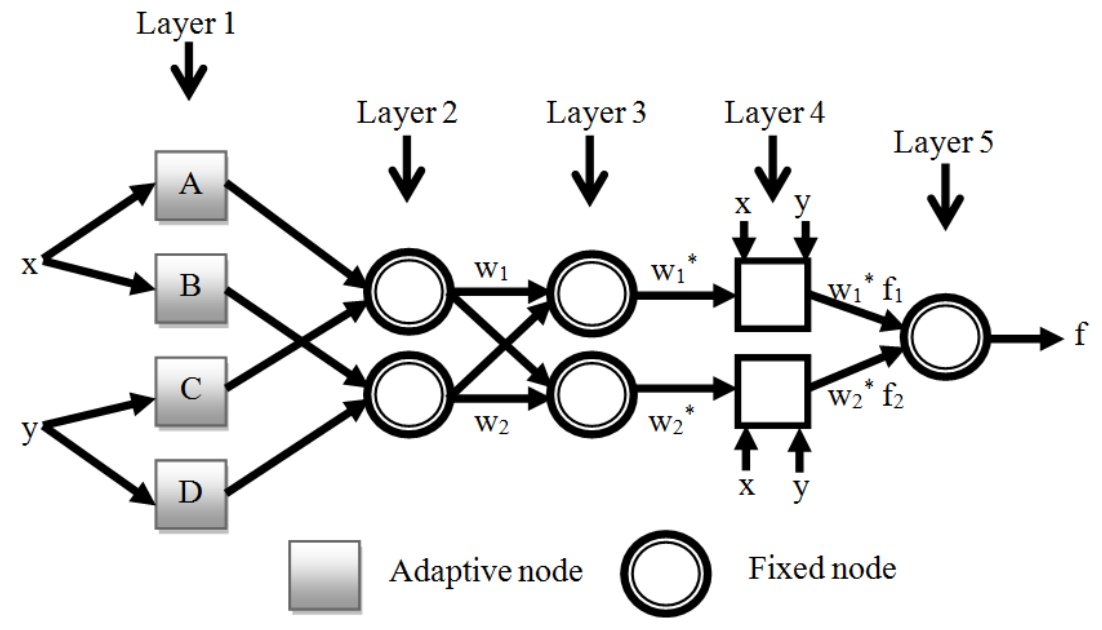

Fig. 3 ANFIS structure

The fuzzy IF-THEN rules of Takagi and Sugeno's class and two inputs for the first-order Sugeno are employed for the purposes of this study:

$$
\text { if } x \text { is } A \text { and } y \text { is } C \text { then } f_{1}=p_{1} x+q_{1} y+r_{1}
$$

The first layer is made up of input parameters MFs, and it provides input values to the following layer. Each node here is considered as an adaptive node having a node function $\mathrm{O}=\mu_{\mathrm{AB}}(\mathrm{x})$ and $\mathrm{O}=\mu_{\mathrm{CD}}(\mathrm{x})$ where $\mu_{\mathrm{AB}}(\mathrm{x})$ and $\mu_{\mathrm{CD}}(\mathrm{x})$ are membership functions. Bell-shaped membership functions having the maximum value (1.0) and the minimum value $(0.0)$ are selected so that

$$
\mu(x)=\operatorname{bell}\left(x ; a_{i}, b_{i}, c_{i}, d_{i}\right)=\frac{1}{1+\left(\frac{x-c_{i}}{a_{i}}\right)^{2 b_{i}}}
$$

where $\left\{a_{i}, b_{i}, c_{i}, d_{i}\right\}$ are parameter sets. The parameters of this layer are designated as premise parameters. Here, $\mathrm{x}$ and $\mathrm{y}$ are inputs to the nodes.

The membership layer is the second layer. It looks for the weights of every membership function. This layer gets the receiving signals from the preceding layer and then it acts as a membership function to the representation of the fuzzy sets of each input variable, respectively. Second layer nodes are non-adaptive. The layer acts as a multiplier for the receiving signals and sends out the outcome in $\mathrm{w}_{\mathrm{i}}=\mu_{\mathrm{AB}}(\mathrm{x}) \cdot \mu_{\mathrm{CD}}(\mathrm{y})$ form. Every output node exhibits the firing strength of a rule. 
The next layer, the third one, is known as the rule layer. All neurons here act as a precondition matching the fuzzy rules, i.e. each rule's activation level is calculated whereby the number of fuzzy rules is equal to the quantity of layers [13]. Every node computes the normalized weights. The nodes in the third layer are also considered non-adaptive. Each of the node computes the value of the rule's firing strength over the sum of all rules' firing strengths in the form of $\mathrm{w}_{\mathrm{i}}{ }^{*}=\mathrm{w}_{\mathrm{i}} /\left(\mathrm{w}_{1}+\mathrm{w}_{2}\right), \mathrm{i}=1,2$. The outcomes are referred to as the normalized firing strengths.

The fourth layer is responsible for providing output values as a result of the inference of rules. This layer is also known as the defuzzification one. Every fourth layer node is an adaptive node having node function $\mathrm{O}_{\mathrm{i}}^{4}=\mathrm{w}_{\mathrm{i}}{ }^{*} \mathrm{xf}=\mathrm{w}_{\mathrm{i}}{ }^{*}\left(\mathrm{p}_{\mathrm{i}} \mathrm{x}+\mathrm{q}_{\mathrm{i}} \mathrm{y}+\mathrm{r}_{\mathrm{i}}\right)$. In this layer, $\left\{\mathrm{p}_{\mathrm{i}}, \mathrm{q}_{\mathrm{i}}\right.$, $r_{i}$ \} is a variable set. The variable set is designated as consequent parameters.

The fifth and final layer is known as the output one. It adds up all the receiving inputs from the preceding layer. Thereafter, it converts the fuzzy classification outcomes into a binary (crisp). The single node of the 5th layer is considered non-adaptive. This node calculates the total output as the whole sum of all the receiving signals,

$$
\mathrm{O}_{\mathrm{i}}^{5}=\sum_{\mathrm{i}} \mathrm{w}_{\mathrm{i}}^{*} \mathrm{xf}=\frac{\sum_{\mathrm{i}} \mathrm{w}_{\mathrm{i}}^{*} \mathrm{f}}{\sum_{\mathrm{i}} \mathrm{w}_{\mathrm{i}}}
$$

In the process of identification of variables in the ANFIS architectures, the ELM or Extreme Learning Machine is applied. The functional signals progress until the 4th layer whereby the hybrid learning algorithm passes. Further, the consequent variables are found by the least squares estimation. In the backward pass, the error rates circulate backwards and the premise variables are synchronized through the gradient decline order.

ELM or Extreme Learning Machine is an algorithm for training of neural networks. The type of neural networks which are trained by ELM is single hidden layer feed forward networks. Fig. 4 shows the structure of the single hidden layer feed forward networks which are trained by ELM algorithm. The main advantage of the ELM algorithm is easy application, shot training time and good generalization of results.

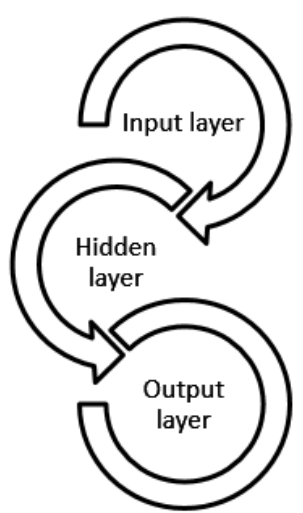

Fig. 4 ELM structure 


\section{RESULTS}

A comprehensive research is performed using the given set of input variables. Basically, an ANFIS model is built by the functions for each combination and then respectively trained for single epoch. Subsequently, the achieved performance is reported. In the beginning only one input parameter influence is examined. From the outset, the most influential input in the prediction of the output is identified and determined. ELM forecasting performances are analyzed based on root mean square error (RMSE) and coefficient of determination $\left(\mathrm{R}^{2}\right)$. The input variable with the lowest number of errors (RMSE) has the highest influence on the output parameter or the most relevance in regards to the outcome. Figs. 5-8 show the forecasting of the laser weld geometrical parameters by the ELM algorithm. A high forecasting accuracy based on the coefficient of determination can be observed. Also, it can be noticed that the points are mostly aligned, meaning that there are no high errors.

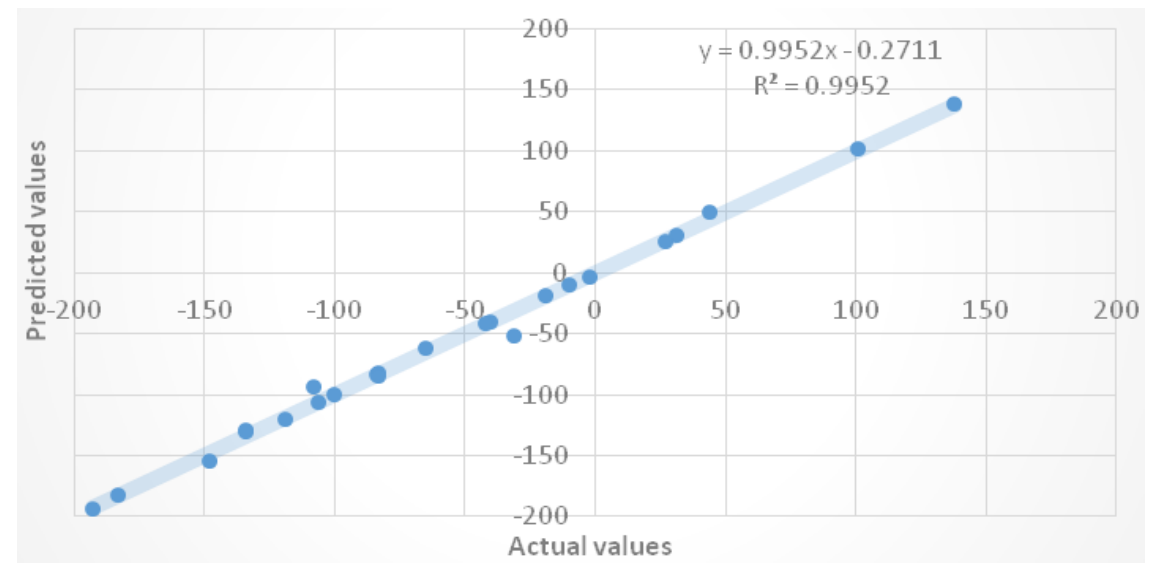

Fig. 5 ELM forecasting of laser weld geometrical parameters: height of weld front

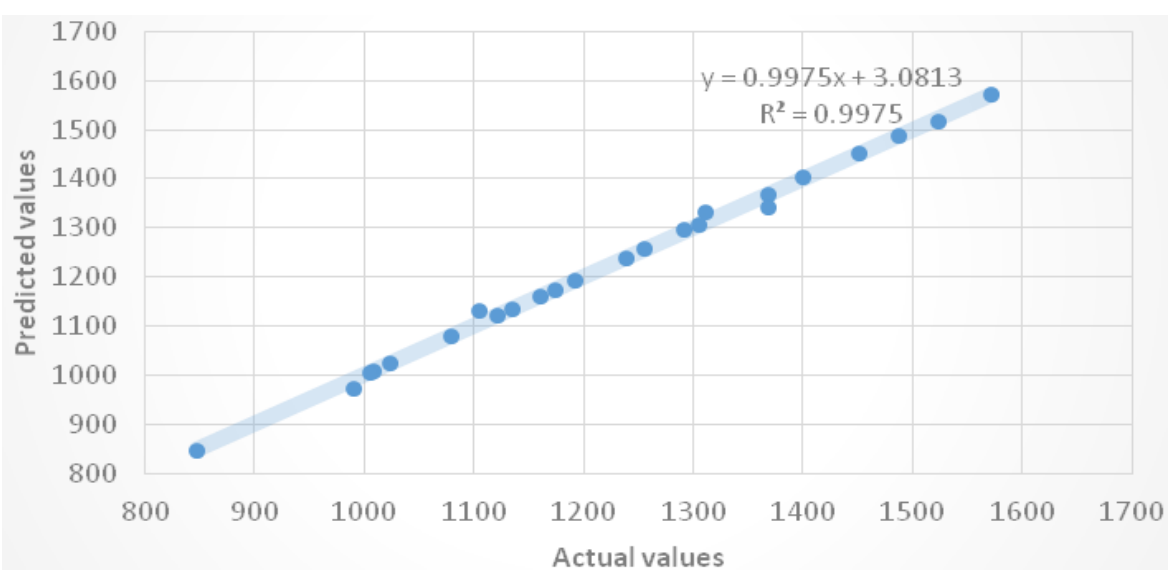

Fig. 6 ELM forecasting of laser weld geometrical parameters: width of weld front 


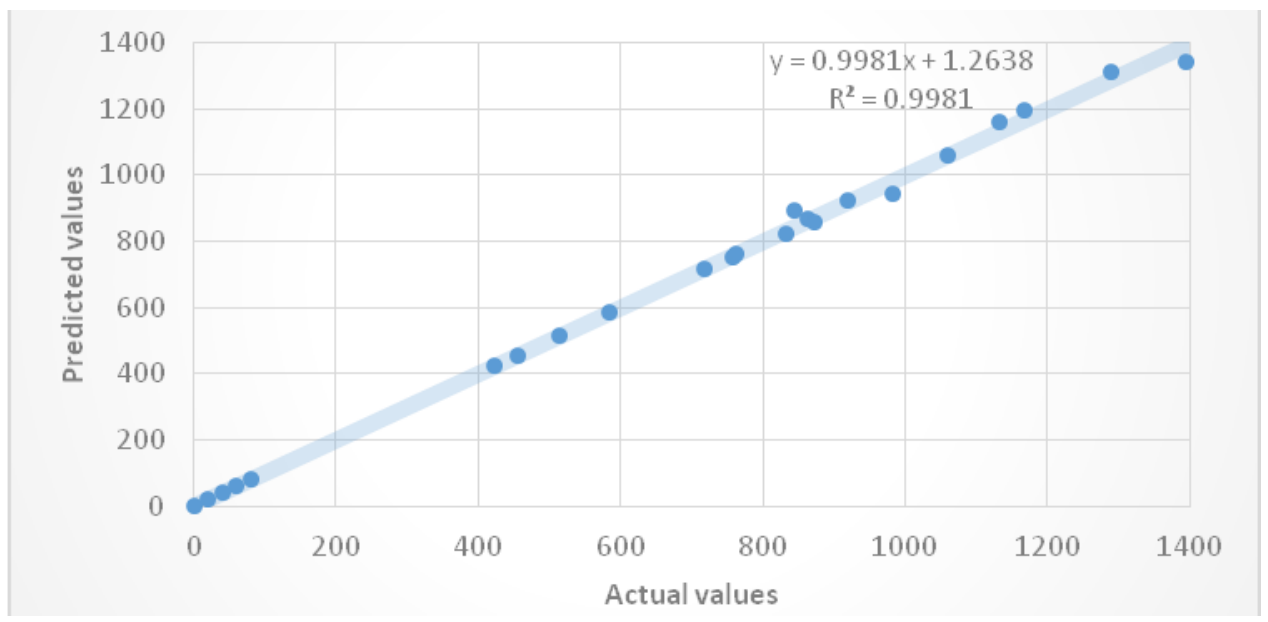

Fig. 7 ELM forecasting of laser weld geometrical parameters: width of weld back

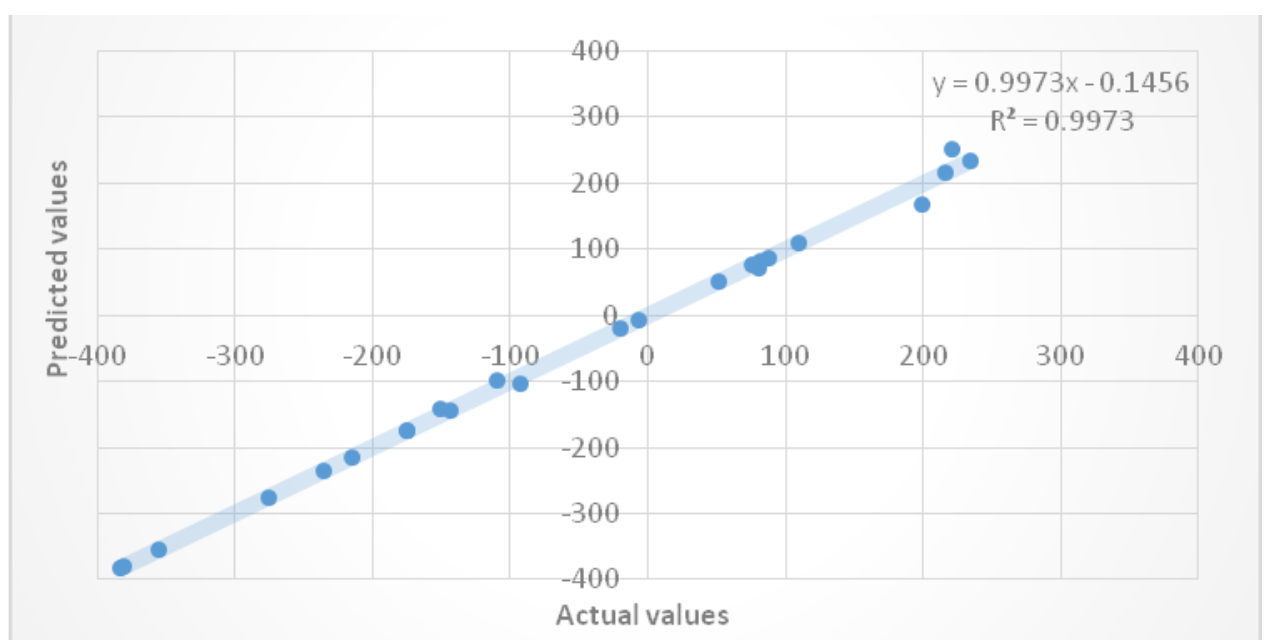

Fig. 8 ELM forecasting of laser weld geometrical parameters: height of weld back

Tables 2-5 show the ELM forecasting performances based on two indicators. Also for the sake of comparison ANN and GP results are also presented. ANN and GP present two different approaches of artificial intelligence. Based on the comparisons one can conclude that the ELM has better forecasting performances than ANN and GP.

Table 2 ELM, ANN and GP models for weld front height prediction

\begin{tabular}{ccrccc}
\hline \multicolumn{2}{c}{ ELM } & \multicolumn{2}{c}{ ANN } & \multicolumn{2}{c}{ GP } \\
\hline RMSE & $\mathrm{R}^{2}$ & RMSE & $\mathrm{R}^{2}$ & RMSE & $\mathrm{R}^{2}$ \\
5.7326 & 0.9952 & 12.1997 & 0.9781 & 17.1592 & 0.9567 \\
\hline
\end{tabular}


Table 3 ELM, ANN and GP models for weld front width prediction

\begin{tabular}{ccrcrc}
\hline \multicolumn{2}{c}{ ELM } & \multicolumn{2}{c}{ ANN } & \multicolumn{2}{c}{ GP } \\
\hline RMSE & $\mathrm{R}^{2}$ & RMSE & $\mathrm{R}^{2}$ & RMSE & $\mathrm{R}^{2}$ \\
9.2444 & 0.9975 & 22.5804 & 0.985 & 41.4980 & 0.9494 \\
\hline
\end{tabular}

Table 4 ELM, ANN and GP models for weld back width prediction

\begin{tabular}{rcrcrc}
\hline \multicolumn{2}{c}{ ELM } & \multicolumn{2}{c}{ ANN } & \multicolumn{2}{c}{ GP } \\
\hline RMSE & $\mathrm{R}^{2}$ & RMSE & $\mathrm{R}^{2}$ & RMSE & $\mathrm{R}^{2}$ \\
18.7626 & 0.9981 & 73.2556 & 0.9708 & 108.4139 & 0.936 \\
\hline
\end{tabular}

Table 5 ELM, ANN and GP models for weld back height prediction

\begin{tabular}{cccccc}
\hline \multicolumn{2}{c}{ ELM } & \multicolumn{2}{c}{ ANN } & \multicolumn{2}{c}{ GP } \\
\hline RMSE & $\mathrm{R}^{2}$ & RMSE & $\mathrm{R}^{2}$ & RMSE & $\mathrm{R}^{2}$ \\
9.9006 & 0.9973 & 36.6879 & 0.9631 & 44.2840 & 0.9462 \\
\hline
\end{tabular}

\section{CONCLUSION}

Forecasting of the laser weld geometrical parameters is complex due to many indicators and factors Therefore, a new approach is proposed in this study in order to overcome the difficulties of the laser weld geometrical parameters forecasting by removing some unnecessary input parameters. A systematic approach is applied with the aim to select the most influential parameters for the laser weld geometrical parameters forecasting by the ANFIS methodology. The ANFIS is used to eliminate vagueness in the laser welding process and to produce the best forecasting conditions. The proposed ANFIS model is used to convert the complicated multiple performance characteristics into the single multi response performance index. As a result, the forecasting methodology developed in this research is useful for enhancing the multiple performances characterizing laser welding analyses.

In this study the main aim is to establish a forecasting algorithm for laser weld geometrical parameters based on input machining conditions. The algorithm is based on an artificial intelligence approach. The main advantage of the approach lies in the fact that it requires no knowledge of the internal physical model of the laser welding process. There is only the need to acquire training data pairs for the AI technique. The algorithm is based on an extreme learning machine which is one type of training algorithm for artificial neural networks. Based on the obtained results, the ELM has shown better performances than other AI techniques.

\section{REFERENCES}

1. Schweier, M., Haubold, M.W., Zaeh, M.F., 2016, Analysis of spatters in laser welding with beam oscillation: A machine vision approach, CIRP Journal of Manufacturing Science and Technology, 14, pp. 35-42.

2. Zhao, Y., Zhu, K., Ma, Q., Shang, Q., Huang, J., Yang, D., 2016, Plasma behavior and control with small diameter assisting gas nozzle during CO2 laser welding, Journal of Materials Processing Technology, 237, pp. 208-215.

3. Mi, G., Xiong, L., Wang, C., Hu, X., Wei, Y., 2016, A thermal-metallurgical-mechanical model for laser welding Q235 steel, Journal of Materials Processing Technology, 238, pp. 39-48. 
4. Shanmugarajan, B., Shrivastava, R., Sathiya, P., Buvanashekaran, G., 2016, Optimisation of laser welding parameters for welding of P92 material using Taguchi based grey relational analysis, Defence Technology, 12(4), pp. 343-350.

5. Chen, M., Xu, J., Xin, L., Zhao, Z., Wu, F., 2016, Comparative study on interactions between laser and arc plasma during laser-GTA welding and laser-GMA welding, Optics and Lasers in Engineering, 85, pp.1-8.

6. Cai, X., Li, H., Wei, H., Yang, L., Gao, Y., 2014, Effect of laser on the welding process of shortcircuiting transfer MIG welding of aluminum alloys, The International Journal of Advanced Manufacturing Technology, 75(9-12), pp. 1829-1836.

7. Chen, L., Zhou, L., Tang, C., Huang, W., Wang, C., Hu, X., Wang, J., Yan, F., Wang, X., Jiang, Z., Shao, X., 2014, Study of laser butt welding of SUS301L stainless steel and welding joint analysis, The International Journal of Advanced Manufacturing Technology, 73(9-12), pp. 1695-1704.

8. Chen, Y.B., Feng, J.C., Li, L.Q., Li, Y., Chang, S., 2013, Effects of welding positions on droplet transfer in $C O 2$ laser-MAG hybrid welding, The International Journal of Advanced Manufacturing Technology, 68(5-8), pp. 1351-1359.

9. Huang, G.B., Zhu, Q.Y., Siew, C.K., 2006, Extreme learning machine: theory and applications, Neurocomputing, 70(1-3), pp. 489-501

10. Huang, G.B., Chen, L., Siew, C.K., 2006, Universal approximation using incremental constructive feedforward networks with random hidden nodes, IEEE Trans. Neural Networks, 17(4), pp. 879-892.

11. Liang, N.Y., Huang, G.B., Saratchandran, P., Sundararajan, N., 2006, A fast and accurate online sequential learning algorithm for feedforward networks, IEEE Transactions on neural networks, 17(6), pp. 1411-1423.

12. Koza, J.R., 1992, Genetic Programming: On the Programming of Computers by Natural Selection, A Bradford Book, The MIT Press, Cambridge, Massachusetts, London.

13. Pamučar, D., Ćirović, G., 2018, Vehicle route selection with an adaptive neuro fuzzy inference system in uncertainty conditions, Decision Making: Applications in Management and Engineering, 1(1), pp. 13-37. 